\title{
0 processo de cuidar participante com um grupo de gestantes: repercussões na saúde integral individual-coletiva
}

\author{
The participant caring process with \\ a group of pregnant: impact in the individual \\ and collective health
}

1 Curso de Enfermagem, Universidade do Sul de Santa Catarina. Av. José Acácio M oreira 787, 88704-900, Tubarão SC reginadelfino@unisul.br 2 Universidade Federal de Santa Catarina. Universidade do Sul de Santa Catarina.

3 Acadêmica colaboradora da pesquisa.

Curso de Enfermagem

Universidade do Sul

de Santa Catarina.
Abstract To study the impact of the use of a participant caring process on the individual and collective health care applied to a group of pregnant. The study was carried out through health care practices with ten pregnant individuals from September to December, 2002. Group activities were developed in six health workshops followed by a home visit to each participant. Using qualitative approach, data were collected through participant observations and interviews during the workshops and home visits, as designed in the Ecological and Holistic Care Reference. The effects of the participant health care were identified trough a process of analysis, and synthesis in the following dimensions: (a) the pregnant woman with herself; (b) the pregnant woman with her baby and family members; (c) the pregnant woman and family members with the community. The search for knowledge based on the participant approach influenced the enlargement of the concept of health and citizenship of pregnant women and their environment. The use of new paradigm approaches can contribute to promoting health as well as to subsidizing interdisciplinary studies.

Key words Collective health, Participant care, Individual and collective health, Integral health, Maternal health
Resumo 0 artigo tem como objetivo conhecer a repercussão da aplicação de um processo de cuidar participante na saúde integral individual-coletiva de um grupo de gestantes. 0 estudo foi realizado através de atividade prática de cuidado em saúde, desenvolvida com um grupo de dez gestantes, no período de setembro a dezembro de 2002. As atividades grupais se deram em seis oficinas de saúde, ao término das quais foi realizada uma visita domiciliar a cada uma das participantes. Numa abordagem qualitativa, o levantamento dos dados foi realizado pela observação participante com entrevista nas dinâmi cas de oficinas e nas visitas domiciliares, delineadas pelo Referencial do Cuidado Holístico-Ecológico. Através do processo de análise-reflexão-síntese, foram identificadas as repercussões do desenvolvimento do processo de cuidar participante nas seguintes dimensões: a gestante com ela própria; a gestante com o seu be bêe com os familiares; e os familiares e a gestante com a comunidade. A busca do conhecimento alicerçada na abordagem participante influenciou na ampliação do concei to de saúde e de cidadania no contexto das gestantes e dos seus coletivos. A utilização de abordagens dos novos paradigmas pode contribuir para a construção do conhecimento e com o processo de promoção da saúde, bem como subsidiar trabalhos interdisciplinares.

Palavras-chave Saúde coletiva, Cuidar participante, Saúde individual-coletiva, Saúde integral, Saúde materna 


\section{Introdução}

Repensar a atenção à saúde da mulher, mais especificamente no processo gestacional, nos remete aos programas desenvolvidos nos serviços de saúde em nosso país.

Nas últimas décadas a atenção à saúde da mulher tem sido alvo de programas como 0 Programa de Assistência Integral à Saúde da Mulher (PAISM), implantado em meados dos anos 80 , com o intuito de atender a mulher de forma integral, sendo um dos seus objetivos reduzir os riscos referentes ao pré natal eao parto. No entanto, embora pautado em diretrizes que propõem a assistência integral à saúde da mulher, ainda se observa, no seu desenvolvimento, a fragmentação das ações direcionadas a este grupo da população.

Nos serviços de saúde, durante anos, a assistência à gestante vem sendo oferecida quase que exclusivamente vinculada à consulta médica individual. As ações de saúde não propiciam um acolhimento às ansiedades, às queixas e temores associados culturalmente à gestação. Desta forma, a gestação é conduzida pelos profissionais de saúde de modo intervencionista, tornando a assistência e as atividades educativas fragmentadas, sem que a realidade da mulher gestante seja tratada na sua individualidade e integralidade.

A concepção reducionista de educação em saúde pouco contribui para as necessidades educativas individuais e coletivas, dificultando a tomada de consciência de suas potencialidades pela população.

Capra (2002) refere que para superar esse modelo de assi stência à saúde é necessária uma profunda revolução cultural e a adoção de um conceito holístico e ecológico de saúde, na teoria e na prática. Isso requer uma mudança conceitual na ciência médica, como também a ree ducação maciça do público.

Patrício (1995b) refere que educar representa um processo cultural, ou seja, um processo de interações humanas fundamentado em suas crenças, seus valores, seus conhecimentos e suas práticas, incluindo aquelas de participação política, aprendidas-ensinadas de diferentes maneiras através da sua história de vida, e que guiam, de certa forma, suas ações no cotidiano do processo de viver.

Em vista desses pressupostos, entendemos que o contexto grupal desenvolve naturalmente um espaço para o movimento da promoção da saúde através de um processo de ensinar-aprender. As ações educativas em saúde mediante ati- vidades grupais com indivíduos em situação de vida comum podem se constituir num método privilegiado de investigação-intervenção. Diante destas considerações, elaboramos a seguinte pergunta: Quais as repercussões da aplicação de um processo de cuidar participante na saúde integral individual-coletiva de um grupo de gestantes?

Partindo deste princípio, desenvolvemos um estudo com um grupo de gestantes de Santa $\mathrm{Ca}$ tarina, que se constituiu numa dissertação de mestrado em saúde coletiva (Delfino, 2003), tendo como objetivo conhecer as repercussões da aplicação de um processo de cuidar participante na saúde integral individual-coletiva de um grupo de gestantes.

Adotamos o método qualitativo de pesquisa através de uma prática em saúde de cunho participante, fundamentada no Referencial do Cuidado Holístico-Ecológico - CHE - de Patrício (1996).

O referencial do CHE preconiza que saúde é um conceito subjetivo, desenvolvido pelo sujeito e seu coletivo a partir das suas representações. Considera que ter saúde é desenvolver possibilidades/recursos individuais e coletivos para promover e restaurar o seu bem viver, contando com recursos de diferentes dimensões: biológicas, afetivas, ambientais, espirituais, inclusive de serviços de saúde, educação e promoção social que percebam o ser humano holisticamente.

O processo de Cuidar Holístico-Ecológico focaliza os princípios de saúde coletiva valorizando o individual. Nesse aspecto reporta a questão da dimensão individual, uma vez que cada indivíduo, na sua subjetividade e unicidade, constrói edesenvolve o coletivo (Patrício, 1996).

A superação do modelo fragmentado, na saúde coletiva, requer a inclusão de novos referenciais teórico-metodológicos, cujas abordagens privilegiem a promoção da saúde individual-coletiva e da qualidade de vida como um tema inerente a esta área.

\section{0 referencial teórico metodológico}

O desenvolvimento teórico metodológico do estudo foi desenvolvido nos princípios da abordagem qualitativa de pesquisa segundo M inayo (1994) e Patrício (1996). Para as autoras, a pesquisa qualitativa possibilita trabalhar com os universos dos significados e atitudes dos sujeitos, dando ênfase ao processo de como os fenô- 
menos ocorrem. Ainda segundo Patrício (1996, 1999), estes métodos representam a possibilidade de operacionalização das concepções que emergem dos novos paradigmas, em especial os que salientam a subjetividade humana em suas crenças, valores e práticas em determinado contexto, e as repercussões em sua qualidade de vida.

Para nortear nossas ações, adotamos o Referencial do Cuidado Holístico-Ecológico (CHE) de Patrício (1996), cujos fundamentos são baseados nos princípios dos novos paradigmas de entendimento do ser humano sociocultural. De acordo com Patrício, o referencial do CHE foi construído especialmente a partir das concepções de Leininger e de Gramsci sobre o "cuidado cultural" e o "ser humano sociocultural", respectivamente.

Para a autora, o foco deste referencial é o ser humano, na sua unidade e diversidade, na sua totalidade individual e coletiva, em relação recíproca com o meio ambiente natural e social; nas suas expectativas individuais e coletivas; seus sentimentos e sua cultura em seus valores, suas crenças e práticas de saúde, sua história de vida; nas suas condições de crescimento e desenvolvimento, e nos seus recursos em todas as dimensões, inclusive afetivas, para o atendimento de suas necessi dades de bem viver no mundo, ou seja, seu processo de viver saudável.

A práxis desse referencial éum processo dialético, que se dá pela dinâmica contínua da promoção de integração de conhecimentos e saberes, de energias, criações e sentimentos que geram possibilidades de transformação. Dá ensejo ao desenvolvimento de propriedades de trabalhar as questões sociais limitantes e transformá-las em possibilidades de viver saudável, seja quando 0 estudo objetiva a produção de conhecimento aplicado, seja quando o próprio estudo origina situações de mudança em favor dos pesquisados.

Com base no referencial adotado, elaboramos pressupostos que nortearam o nosso olhar durante o desenvolvimento das atividades com o grupo de gestantes sujeitos do nosso estudo, a saber:

Grupo de gestantes: é o ambiente micro, e dinâmico, que objetiva a promoção da saúde integral individual-coletiva das gestantes, mediada pelas interações que nele ocorrem. A participação no grupo permite à gestante ser multiplicadora de saúde no seu coletivo. As interações geradas entre as participantes e os profissionais da saúde formam uma teia que possibilita a promoção da saúde integral com repercussões desse processo no individual-coletivo.
Possibilidades de saúde integral na gestação: são os recursos existentes no contexto da gestante e do seu bebê, podendo estar relacionados ao atendimento das suas necessidades e que são essenciais à vida e ao bem viver. As possibilidades de saúde integral na gestação estão na dependência direta dos recursos individuais e dos recursos coletivos. Estas possibilidades podem ser caracterizadas pela mediação da pesquisadora, o grupo de gestantes, a equipe interdisciplinar e pelo coletivo da gestante.

Promoção da saúde integral individual-coletiva: é um processo realizado pelos profissionais da saúde junto com os indivíduos, com vistas à transformação das suas limitações em possibilidades de viver saudável. Visa ainda promover a conscientização dos sujeitos para a participação nas decisões que envolvem o seu processo de viver, buscando contemplar as questões de cidadania na dimensão individual-coletiva.

0 método da pesquisa foi realizado mediante os três momentos propostos pelo referencial do CHE, "entrando", "ficando" e "saindo do campo". Esses momentos ocorrem a cada encontro, numa inter ação dinâmica, interligada e constante.

0 "entrando no campo" constitui as atitudes e processos de aproximação dos sujeitos, do local, da elaboração e testes dos instrumentos, da apresentação da proposta da pesquisa e o seu planejamento participativo, bem como da apresentação dos preceitos éticos que envolvem o estudo de pesquisa.

0 "ficando no campo" representa as diferentes etapas de interação com os sujeitos, quando se desenvolvem as técnicas de levantamento dos dados. Neste estudo, o levantamento dos dados ocorreu nos encontros grupais e nas visitas domiciliares. Através da técnica de oficinas, os dados foram levantados mediante a realização de O bservação Participante e Entrevistas.

Os dados obtidos foram registrados no "diário de campo" e nos instrumentos de entrevista. A análise dos dados foi realizada no decorrer do estudo concomitantemente ao levantamento dos dados à luz dos referenciais propostos por M inayo (1994) e Patrício (1996, 1999). Conforme o Referencial do CHE, a análise foi desenvolvida por um processo de análise-reflexãosíntese, favorecendo o exercício da intuição reflexiva e criativa junto dos dados.

0 "saindo do campo" pode ocorrer gradativamente no decorrer do processo de coleta de dados, mas tem seu momento específico no final do processo, podendo vir a ser desenvolvido 
de diversas formas, de acordo com a realidade encontrada.

\section{0 processo de cuidar participante e os temas emergentes}

A operacionalização do CHE neste estudo desenvolveu um percurso que representa o processo de pesquisar-cuidando ou cuidar-pesquisando, a saber:

Reconhecimento da realidade: deu-se através do levantamento de dados com os sujeitos da pesquisa no grupo de gestantes e também através de uma visita domiciliar. Os dados foram levantados utilizando-se as técnicas de observação participante, entrevista e a técnica de oficinas.

Compreensão da realidade: mediantea identificação das situações de saúde que interferem nas possibilidades e limitações de bem viver das gestantes. Esta etapa foi desenvolvida pela análise-reflexão-síntese de todo o processo grupal e individual, buscando identificar as categorias de análise, mais especificamente crenças, valores, expectativas, desejos, necessidades, sentimentos, conhecimentos, práticas de saúde, possibilidades (recursos individuais e coletivos), limitações, e as repercussões do trabal ho de grupo na saúde integral individual-coletiva nos ambientes da gestante (família, escola, trabalho, comunidade).

Transformação da realidade: durante o processo de cuidar grupal e individual, foi realizada implementação de cuidados para promover a transformação das limitações em possibilidades de bem viver.

0 processo de interação com as gestantes ocorreu no Serviço de Assistência Integrada à Saúde(SAIS), ambulatório-escola do curso de enfermagem da Universidade do Sul de Santa Catarina (Unisul), localizada na cidade de Tubarão (SC). 0 estudo foi realizado entre os meses de setembro e dezembro de 2002, num total de seis encontros quinzenais e uma visita domiciliar a cada uma das participantes no final dos encontros.

Foram sujeitos do estudo 10 gestantes que participaram de pelo menos quatro dos seis encontros realizados.

Como recurso educativo, nas dinâmicas grupais utilizamos a técnica de oficinas, procedendo-se ao levantamento dos dados através da técnica de observação participante com entrevistas col etivas. A técnica de oficinas, de acordo com Patrício (1999), permite pesquisar e agir em diferentes campos de atuação. N ela desenvolvem-se discussão e reflexão de conteúdos e de formas de interação que são originadas das expectativas dos participantes, de suas culturas (crenças, valores, conhecimentos, normas e práticas pessoais e profissionais) e sentimentos expressos no decorrer do encontro. Os integrantes da oficina, mediados pelo coordenador, constroem o conteúdo a partir dos depoimentos dos participantes sobre as vivências das atividades e dos significados dos sujeitos.

A técnica de oficina permitiu aos participantes a possibilidade de compartilhar sentimentos, de criar, e de aprender de forma diferente, além de estimulá-los para o compromisso da socialização com os seus pares sobre as idéias que emergiram das vivências grupais. No desenvolvimento das oficinas, em consonância com o processo metodológico adotado, recorre mos a recursos educativos terapêuticos como a simbolização, as perguntas semi-estruturadas, 0 ouvir-escutar, atividades de relaxamento, a musicoterapia e a reflexão.

Os momentos vivenciados no grupo objetivaram conhecer, compreender e identificar a transformação da realidade. Esse processo se deu mediante a construção coletiva através do diálogo, para identificar, aprender, criar, compartilhar e refletir sobre as possibilidades e limitações referentes à saúde integral individualcoletiva das gestantes. As atividades, direcionadas por uma metodologia de caráter participante e transformador, proporcionaram a reflexão conjunta sobre as semelhanças e diversidades de concepções acerca da saúde e das práticas individuais e coletivas das participantes.

$\mathrm{Na}$ primeira oficina realizou-se o levantamento das expectativas das gestantes referentes ao processo de grupo e, a cada oficina realizada, as gestantes escolhiam o assunto a ser discutido no encontro posterior, delimitando-se então os seguintes temas: desconfortos na gravidez; cuidados com os seios na amamentação; o parto; cuidados com a mãe ecom o bebêno pós-parto; discussão de todos os temas trabal hados no grupo.

A partir das temáticas de escolha das gestantes, outros temas emergiram em conseqüência das dimensões e reflexões nas oficinas, durante o processo de cuidar participante. Tais temas estavam relacionados aos sentimentos das participantes sobre a sua gravidez, bem como à percepção sobre o processo saúde-doença, às práticas de cuidados, à saúde na gravidez e questões relativas à cidadania. 
Quanto aos sentimentos relacionados à gravidez, destacamos o seguinte depoimento:

É meu primeiro filho; estou com medo de algumas coisas diferentes, não estou me sentindo legal. Tenho sentimentos que não gostaria de ter. Por que não faço um carinho na barriga? Acho que quando meu filho nascer não vou gostar dele. M e sinto perdida. Q uando descobri que estava grávida meu mundo desabou. Às vezes fico deprimida, me pergunto como vou ficar: velha ebarriguda? Não planejei a gravidez (Girassol).

A prática do Referencial do CHE evidencia que nas técnicas de oficina muitas histórias de vida emergem durante as atividades. Nesse processo, as gestantes expressaram os seus sentimentos de ansiedade, alegria e desilusões. Muitas delas, de acordo com os dados obtidos, estavam vivenciando situações limitantes, que se expressavam por tristeza, desânimo, culpa, insegurança, bem como queixas de falta de afeto e de apoio, o que impedia 0 atendimento das suas necessidades nos seus processos de viver. Essas limitações são decorrentes das interações que ocorrem com elas mesmas e com o coletivo.

As interações iniciais entre os participantes têm por finalidade conhecer e compreender as suas realidades sem, no entanto, realizar cuidados à saúde. Todavia, em al gumas situações vivenciadas no grupo, emergiu a necessidade de intervenção, fruto de um processo de observação, interpretação e reflexão e, sobretudo, de razão e sensibilidade.

A percepção sobre a saúde foi assim manifestada pela participante Copo de Leite: Tenho saúde quando estou bem em tudo, bem de cabeça. É ter boa alimentação, higiene, ter uma convivência harmoniosa com a família e com os amigos; estar de bem com a vida.

0 depoimento desta participante, sobre a percepção referente ao processo saúde-doença, revelou que este vai além das dimensões biológicas, incluindo, entre outras, a dimensão afetiva.

Outras percepções foram verbalizadas e nos levaram a buscar no referencial adotado que "estar" ou "ser" doente, para o ser humano, é sentir dificuldades (limitações) para atender necessidades de bem viver, ou mesmo apenas viver. Essas situações de saúde-doença nos relatos do grupo foram expressadas verbalmente, através de queixas e dos sinais do corpo, e diante das atitudes interacionais com o seu coletivo.

As práticas de cuidados com a saúde na gravidez neste grupo estudado estavam relacionadas aos cuidados dispensados pelos familiares, assim como a consulta médica era recurso utilizado para cuidar da saúde, na maioria dos casos.

Sobre as práticas de cuidado com a saúde, H ortênsia assim se manifestou: Antes da gravidez eu não cuidava da minha saúde, não fazia preventivo, não fazia exame médico. Depois que fiquei grávida passei a me cuidar mais, ir ao mé dico, participar de grupo de gestante; tinha consciência que se não me cuidasse poderia acontecer alguma coisa comigo ou com o neném, e eu ia me sentir culpada.

Nas dinâmicas das oficinas, os depoimentos da maioria das gestantes revelaram a crença na necessidade de cuidar da saúde mesmo na ausência de doença. Por sua vez, algumas referiram que o cuidado à saúde é necessário somente na presença de doença.

No trabalho participante, de acordo com 0 referencial adotado, há situações de saúde-doença que são compreendidas como limitantes, havendo "necessidade de repadronização", ou seja, requerem modificações parciais ou totais das práticas de cuidado, para possibilitar um viver saudável. N essa situação, houve necessidade de intervenção com o intuito de repadronizar crenças e valores.

Através de uma relação dialógica voltada à compreensão dos significados, das crenças e do modo de viver pudemos promover momentos de "troca de saberes", "de valores", num processo de "mexida na consciência" através do pensar criticamente.

Pesquisando-cuidando, realizamos neste momento 0 ato de cuidar pela mediação do processo de transformação da realidade, pois durante o diálogo nosé possível interferir na consciência humana no sentido de despertar para outras verdades, numa interação educativa.

Segundo o Referencial do CHE, Cuidar édesenvolver ações de promoção da vida, e tratamento de limitações do bem viver dos seres humanos (...); um processo de educação para a vida saudável, incluindo a garantia da democracia, em todos os seus sentidos, políticos e afetivos (Patrício, 1996).

Nesse sentido, o processo dialógico desenvolvido, num enfoque educativo, abrangeu também aspectos diretamente relacionados à cidadania, de direito e dever. A questão dos direitos das gestantes emergiu no grupo e houve exaustiva discussão, mais especificamente, a respeito do direito da presença de um acompanhante no momento do parto, prática que é desenvolvida pelos hospitais que obtiveram o título de Hospital Amigo da Criança. 
Nesta dimensão, esclarecemos sobre a lei no 12.133, sancionada em março de 2002, vigente no Estado de Santa Catarina, a qual permite de forma incondicional a presença de um acompanhante junto com a parturiente no momento do parto. Percebemos que havia entre elas a desconfiança quanto ao cumprimento desta lei nas maternidades.

Refletimos sobre alguns mecanismos que poderiam ser utilizados para fazer valer a Lei do Acompanhante no Parto; dentre eles, destacamos a necessidade de que todas as participantes tivessem conhecimento do número e conteúdo da lei e exigissem o seu cumprimento durante os seus processos de parto.

$\mathrm{Na}$ perspectiva do referencial do $\mathrm{CHE}, \mathrm{O}$ conhecimento dos direitos e deveres de cidadão e dos fatores determinantes do processo saúde-doença já são por si só elementos colaboradores para o bem viver humano (Patrício, 1996).

\section{Conhecendo as dimensões das repercussões do processo de cuidar participante}

As visitas domiciliares realizadas às participantes do estudo possibilitaram conhecer as dimensões das repercussões da aplicação do Processo de Cuidar Participante com o grupo de gestantes, mediante o exercício de análise-reflexão-síntese nos seguintes contextos:

Individual: a gestante "com ela própria";

Coletivo: a gestante "com o seu bebê"; a gestante "com os seus familiares"; os familiares da gestante "com pessoas da comunidade"; e a gestante "com a comunidade".

\section{A gestante com ela própria}

Do ponto de vista individual, percebemos as repercussões em diversas dimensões, como veremos a seguir.

\section{- Repercussões emocionais}

Eu chegava lá no grupo deprimida, parece que era feita uma 'lavagem cerebral' em mim, eu saía de lá outra pessoa. M e senti muito mais pre parada, uma nova mulher. Eu era uma pessoa e, agora sou outra depois que participei do grupo (Flor do Campo).

Estando no grupo eu fiquei muito mais segura em relação à gravidez (Margarida).
Eu acho que o grupo mexeu comigo, (...) estou mais otimista, mais segura das coisas (H ortênsia).

Analisando essas declarações, percebe-se que o grupo, para algumas delas, foi uma espé cie de "respiradouro", que, segundo o Referencial do CHE de Patrício (1996), é representado por momentos de meditação, de reflexões e diálogos que promovem a transformação da vida.

A prática dialógica desenvolvida nas oficinas validou o referencial do $\mathrm{CHE}, 0$ qual prevê a possibilidade da "mexida na consciência" mediante trocas de crenças, valores, saberes e energias, constituindo-se num processo transcultural e transpessoal. 0 diálogo, neste estudo, representou um meio de reflexão sobre a realidade, como, também, a construção de novos saberes com vistas à transformação da realidade.

\section{- A gestante e suas práticas de cuidados à saúde}

$\mathrm{Na}$ ótica das partici pantes, suas percepções sobre a saúde e as suas práticas de cuidados foram ampliadas, transcendendo para dimensões além dos aspectos biológicos. Esta repercussão já havia sido por nós identificada durante as dinâmicas grupais. 0 depoimento a seguir expressa esta transformação: As coisas que aprendi no grupo me fizeram pensar diferente sobre a minha saúde; eu já me cuidava, agora cuido mais ainda (Flor do Campo).

Capra (2002) pontua que o conceito de saúde está fortemente ligado ao contexto cultural em que ele ocorre. Neste aspecto, as participantes passaram a perceber e a valorizar a saúde de um modo diferente, referindo terem mais clareza sobre o processo que leva a desenvolver as práticas de cuidado não como obrigação, mas com consciência. A ampliação de suas concepções está relacionada à repadronização de suas crenças, seus valores e conhecimentos acerca do processo saúde doença.

Entendemos que as ações de promoção da saúde devem ser eminentemente participativas e transformadoras. Assim, atuar em promoção da saúde significa abrir um enorme leque de possibilidades de atuação, dependendo dos contextos socioculturais de cada comunidade, bem como valores verdadeiros que possibilitem uma transformação, conscientização e, portanto, um novo entendimento de uma cidadania que contempla o individual e o coletivo, enfocando a saúde como qualidade de vida (Ferraz, 2000).

Na percepção das gestantes, de acordo com seus depoimentos durante a visita domiciliar, a 
saúde e as suas práticas de cuidado foram redimensionadas a partir dos diálogos reflexivos decorrentes das dinâmicas nas oficinas grupais.

\section{A gestante com outras pessoas}

\section{- A gestante com o seu bebê}

As gestantes passaram a compreen der a gravidez de maneira diferente, a partir das vivências grupais sentindo-se mais próximas do bebê. No momento das visitas domiciliares, aquelas gestantes que referiram durante as oficinas desinteresse pela gravidez, inclusive falta de amor, referiram modificação dos seus sentimentos, 0 que possibilitou a formação do apego entre elas e os seus bebês, como podemos observar nos depoimentos a seguir:

Antes eu não curtia a gravidez; depois fui para o grupo, foi como se tivesse colocado o bebê dentro de mim no grupo. Foi um chamado para a vida, para a realidade. M e senti grávida no grupo, antes não era assim (Flor do Campo).

Depois que passei a participar do grupo, mudou tudo para melhor, mudou com o bebê, vejo o meu filho de modo diferente, com muito amor. Antes do grupo eu não sentia amor pelo bebê, agora estou curtindo muito este momento, (...) passei a ter sentimentos de mãe no grupo (Girassol).

Para Klaus et al. (1993), o apego é crucial para a sobrevivência e desenvolvimento do bebê. $O$ vínculo dos pais com seus filhos deve ser o mais forte de todos os laços humanos.

É importante considerar que algumas gestantes, ao se integrarem nesse estudo, estavam vivenciando situações que impossibilitavam uma interação com o bebê de maneira prazerosa em vista de suas histórias de vida, marcadas pela ruptura dos seus projetos pessoais, por influências das suas crenças, dos seus valores, dos seus sentimentos e das suas expectativas diante da gravidez como um processo definitivo no seu viver. As interações vividas produziram transformações que ocorreram num processo dinâmico, influenciadas pelo microcontexto grupal no sentido de possibilitar-Ihes o desenvolvimento de reflexões sobre o seu processo de maternidade.

\section{- A gestante com os seus familiares}

Na dimensão familiar, um aspecto de transformação na vida de uma das participantes se deu na divisão das responsabilidades conjugais relativas aos cuidados com os filhos, situação que comprometia anteriormente a sua participação efetiva nas atividades grupais.

Culturalmente há uma legitimação do papel feminino na tarefa de cuidar dos filhos, atender a família e cuidar da casa. A atribuição cultural dos diferentes papéis exercidos por homens e mulheres na sociedade é o que define as suas re lações. Essas diferenças de papéis têm reflexos importantes na saúde de cada sexo, e em algumas situaç̃̃es trazendo limitações para as muIheres no sentido de impedir a realização de outras atividades que Ihes proporcionem crescimento pessoal e uma vida mais saudável.

Patrício (1996) enfatiza que a família pode ser uma limitação no processo de viver dos indivíduos, quando impõe normas contrárias às necessidades dos seus membros, ou quando se torna um empecilho para a liberdade de agir dos sujeitos.

Em determinadas situações neste estudo, a família se constituiu numa limitação, quando dificulta 0 atendimento das necessidades das participantes. Nas visitas domiciliares realizadas, algumas mulheres referiram que seus companheiros, inicialmente, não entendiam as suas necessidades de freqüentarem as oficinas, uma vez que algumas delas já eram mães e, na concepção deles, elas possuíam o conhecimento necessário sobre os cuidados de saúde.

0 enfrentamento da situação foi direcionado para o caminho do diálogo e da divisão de responsabilidades, ocorrendo o processo de repadronização no companheiro a partir das próprias transformações na mulher durante a vivência grupal.

\section{- A gestante e seus familiares com a comunidade}

As repercussões do Processo de Cuidar Participante foram também observadas nas interações das participantes do grupo com as pessoas da comunidade, a saber: Passei os conhecimentos que aprendi no grupo para uma amiga que está grávida, ela não pode participar do grupo porque é difícil sair do seu local de trabalho. Inclusive, falei para o marido dela sobre a lei que dá o direito da gestante de ter um acompanhanteno parto. Ele disse que não sabia desse direito evai acompanhála quando ela for ganhar o bebê(Orquídea).

Diante deste depoimento procuramos posteriormente entrar em contato com esse casal para confirmar as repercussões na dimensão coletiva. O btivemos a seguinte fala: Cheguei no hospital junto com a minha esposa esolicitei para 
acompanhá-la e falei da lei do acompanhante. $N$ ão precisei insistir, me deixaram entrar com ela na hora do parto (marido da amiga de Orquídea).

Podemos perceber, a partir desse relato, que as gestantes multiplicaram a discussão sobre a presença de um acompanhante junto da parturiente no momento do parto com os seus pares no coletivo, possibilitando-Ihes tomar conhecimento sobre os seus direitos, bem como reivindicá-los. No cotidiano das gestantes, é comum o desconhecimento sobre os seus direitos durante o processo do nascimento. Por outro lado, muitos serviços de saúde não informam as gestantes sobre os seus direitos. Observa-se nesse particular a importância de os profissionais da saúde promoverem a conscientização dos indivíduos.

Stotz (1993) refere que o indivíduo somente pode conhecer suas possibilidades de vida tornando-se consciente das possibilidades das pessoas nas mesmas condições em que ele se en contra.

Sobre estas questões, D emo (1993) pontua que participação é conquista, é um processo no sentido legítimo do termo: infindável em constante vir-a-ser, sempre se fazendo. Assim, participação é autopromoção e existe como conquista processual. Não existe participação suficiente, nem acabada.

0 processo reflexivo instaurado extrapolou a dimensão do grupo para o coletivo. As participantes perceberam que as discussões sobre os direitos das gestantes não deveriam ficar restritas à dimensão do grupo, mas que outras muIheres poderiam ter acesso a essas informações.

Nessa teia de interações, as participantes mostraram a potencialidade do seu viver individual-coletivo. Isso nos reporta à questão de que o ser humano sozinho não tem o potencial que os outros em coletividade apresentam.

Reafirmando o que propõe o referencial do $\mathrm{CHE}$, o processo reflexivo vivenciado pelas gestantes procurou ajudá-las no desenvolvimento de suas consciências individual-coletivas, no sentido de resgatar a sua cidadania, neste contexto, nas questões de direito e de dever. Isso posto, 0 processo de cuidar possibilita fazer mediação para ajudar o indivíduo a desenvolver potencialidades de participar ativa e politicamente nas decisões que envolvem seu processo de viver coletivo, incluindo suas questões de cidadania.

\section{- Os familiares das gestantes com outras pessoas da comunidade}

As interações estabelecidas a partir das atividades grupais provocaram ainda outras re- percussões além do âmbito familiar, como evidencia este relato: 0 meu marido, me acompanhando no grupo, chegou a ensinar a dona do bar, que estava amamentando o seu bebê, sobre o que ela deveria fazer para rachadura no peito. Disse para ela tomar banho de sol efazer exercícios no peito. Os colegas que estavam no bar ficaram espantados e perguntaram como ele sabia disso, ele respondeu que participou de um grupo de gestantes comigo e aprendeu isso lá (Flor do Campo).

Além das repercussões evidenciadas nos familiares, foi possível perceber que nesse processo de construção individual-coletiva, ultrapassando o contexto grupal para o familiar, a teia de interações criada no grupo gerou transformações nos sujeitos tornando-os co-partícipes do movimento educativo grupal, sendo multiplicadores de saúde no coletivo.

No referencial do CHE o entendimento do sentido de coletivo de todo e qualquer ser humano, baseado na física quântica, é compreendido na afirmação de que nada existe sem 0 sentido do observador, nada existe fora da interação. Toda a qualidade é fruto desse processo de interação e, como qualquer outro elemento na natureza, nenhum indivíduo pode ser compreendido fora de suas relações através da história, pois não é uma entidade portadora de existência independente (Patrício, 1999).

\section{Reflexões finais}

A trajetória trilhada para responder à questão da pesquisa possibilitou realizar uma prática de saúde pautada numa abordagem dialógica que procurou identificar as repercussões da aplicação de um processo de cuidar participante na saúde integral individual-coletiva de um grupo degestantes.

A implementação do estudo dentro da perspectiva qualitativa e participante ocorreu desde o seu princípio através da dinamicidade de promoção da integração de saberes, de energias, criações e sentimentos que geram nova construção de conhecimentos e possibilidades de transformação.

Neste aspecto, o grupo revelou-se como um recurso para as suas participantes, constituindose num espaço para compartilhar experiências, sentimentos e afetos e socialização de saberes técnico-científico e popular. Ocasionou, ainda, uma maior compreensão de si edo mundo bem como a busca das possibilidades - recursos para a saúde integral na dimensão individual-coletiva. 
O convívio com as participantes, além de gratificante, possibilitou aplicar uma abordagem teórico-metodológica que valoriza os sujeitos na sua subjetividade, sem contudo perder de vista o rigor da pesquisa qualitativa. A realização de visita domiciliar como estratégia para a identificação das repercussões neste estudo foi importante por possibilitar uma aproximação com a realidade e cotidiano das gestantes.

A busca do conhecimento alicerçada na abordagem participante, sob o ponto de vista da saúde coletiva, influenciou na ampliação do conceito de saúde e de cidadania no contexto das gestantes e dos seus coletivos.

Neste estudo não se teve a pretensão de impor a modificação de padrões de comportamentos das participantes, por entender que num processo educativo buscam-se conjuntamente caminhos para a super ação das limitações em possibilidades para o processo de viver.

Essa premissa se constitui num desafio para a saúde coletiva, por incorporar uma abordagem teórico-metodológica que val oriza as dimensões dos indivíduos e dos grupos, bem como das representações sociais (M inayo, 2000).

É inegável o valor do desenvolvimento tecnológico e das ciências, particularmente aquelas relacionadas à área da saúde. No entanto, as práticas de saúde que vêm ocorrendo atualmente têm provocado um distanciamento na dimensão das relações entre os profissionais da saúde e os indivíduos, tornando lacunar a qualidade da assistência. Os profissionais de saúde carecem de uma filosofia transformadora das suas práticas cotidianas no sentido de perceberem a dinamicidade das interações entre 0 âmbito individual-coletivo.

Nessa ótica, a saúde coletiva requer uma compreensão dos desafios que se colocam no presente e no futuro em busca de superar a fragmentação da assistência à saúde dos indivíduos.

De acordo com Ferreira (1995), a preocupação com a apreensão da totalidade e a fragmentação da atenção à saúde é um viés positivista que não cabe mais nos dias de hoje.

Sob o ponto de vista da saúde coletiva e tendo em vista as expectativas que depositamos no Projeto deste estudo, estamos convictos de que o processo de pesquisar-cuidando implementado neste estudo pode contribuir com a sociedade, nos seguintes aspectos:

- Servir de subsídio teórico-metodológico para as equipes de saúde e respectivos programas nas suas atividades com grupos específicos, possibilitando a utilização de práticas de promoção da saúde integral individual-coletiva, especialmente, como subsídio de avaliação cotidiana das ações de saúde;

- Contribuir para a prática do ensino na área da saúde, considerando-se que o trabalho com grupos permite a produção de conhecimento no que concerneà área de saúde da mulher, e de outras áreas, constituindo-se num importante recurso para o processo ensino-aprendizagem;

- Colaborar na integração da pesquisa nos trabal hos de campo;

- Possibilitar a implementação de métodos de assistência, que, nessa modalidade desenvolvida, permitiram a transposição de repercussões do indivíduo para o coletivo, na construção de uma teia de interações;

- Expandir as concepções dos novos paradigmas em saúde, com o intuito de contemplar a perspectiva de pensar o processo saúde-doença na multidimensionalidade e no contexto da participação dos sujeitos na promoção da sua saúde.

Considerando que este trabalho representou apenas mais um passo para a realização de caminhadas com grupos, recomendamos:

- Que se desenvolvam outros estudos baseados na proposta participante com o envolvimento da equipe interdisciplinar em saúde no processo, visando à produção de novos conhecimentos e às múltiplas dimensões e conexões que se expressam mediante essa integração.

- Que novos estudos venham a utilizar o referencial do Cuidado Holístico-Ecológico e outros dessa natureza; que sejam de abordagem "sistêmica", ou "holística", uma vez que podem contribuir para uma maior compreensão da construção do conhecimento e do processo de promoção da saúde, bem como subsidiar trabaIhos interdisciplinares.

- Que nos programas de saúde, como o Programa de Saúde da Família, sejam implantados trabal hos com grupos e visitas domiciliares voltados para a avaliação constante das repercussões, bem como dos métodos utilizados.

Ao finalizar estas reflexões, desejamos que os conhecimentos produzidos neste estudo sensibilizem os profissionais de saúde no aperfeiçoamento dessa proposta com grupos específicos em outras realidades. Q ue a saúde coletiva, como campo do conhecimento, abra-se para a utilização de abordagens que superem as limitações do modelo em saúde vigente.

Nesse olhar, há que se construir um novo pensar efazer em relação a esta prática, que requer, além do conhecimento, a mudança de atitudes. 0 que se constitui num grande desafio. 


\section{Colaboradores}

M RR D elfino trabalhou na pesquisa bibliográfica, na sistematização do estudo e na redação; ZM Patrício, na concepção, na orientação da pesquisa bibliográfica e na revisão do texto; AS M artins, na coleta de dados da pesquisa; e M R Silvério na co-orientação e na revisão do texto.

\section{Referências bibliográficas}

Capra F 2002. 0 ponto de mutação: a ciência, a sociedade e a cultura emergente. (23a ed.). Cultrix, São Paulo.

Delfino M RR 2003. 0 processo de cuidar participante com um grupo de gestantes: repercussões na saúde integral individual coletiva. Dissertação de mestrado. Universidade do Sul de Santa Catarina, Tubarão (SC).

Demo P 1993. Participação é conquista: noções de política social participativa. (2a ed.). Cortez, São Paulo.

Ferraz ST 2000. A saúde fora do setor saúde ou lições da Agenda 21. Promoção da Saúde 2(3):12-14.

Ferreira M AFB 1995. Notas sobre a contribuição do cientista social ao campo de saúde. pp. 37-51. In AM Canesqui (org.). Dilemas e desafios das ciências sociais na saúde coletiva. Abrasco-Hucitec, Rio de Janeiro-São Paulo.

Klaus M \& Kennell JH 1993. Pais/bebê: a formação do apego. Artes M édicas, Porto Alegre.

M inayo M CS et al. 1994. Pesquisa social: teoria, método e criatividade. (2a ed.) Vozes, Petrópolis.

M inayo M CS 2000. 0 desafio do conhecimento: pesquisa qualitativa em saúde. (7a ed.) Hucitec-Abrasco, São Paulo-Rio de Janeiro.

Patrício ZM 1995a. A dimensão felicidade-prazer no processo de viver saudável individual e coletivo: uma questão bioética numa abordagem holístico-ecológica. Tese de doutorado em filosofia da enfermagem. Universidade Federal de Santa Catarina, Florianópolis.
Patrício ZM 1995b. "Educação para a saúde”: um processo de interações cultural-afetivas transformando a vida. Florianópolis: UFSC. Trabalho apresentado no $47 \underline{0}$ Congresso Brasileiro de Enfermagem, Goiás.

Patrício ZM 1996. Ser saudável na felicidade-prazer: uma abordagem ética e estética pelo cuidado holístico-ecológico. Universitária/UFPel-PPG em Enfermagem/ UFSC, Pelotas-Florianópolis. (Série Teses em Enfermagem).

Patrício ZM 1999. Qualidade de vida do ser humano na perspectiva de novos paradigmas. pp. 19-88 In ZM Patrício et al. Qualidade de vida do trabalhador: uma abordagem qualitativa do ser humano através de novos paradigmas. Ed. do autor, Florianópolis.

Patrício ZM , Guerra AFS \& M aia PD 1999. De dentro para fora de fora para dentro, pp. 91-126. In ZM Patrício et al. Qualidade de vida do trabalhador: uma abordagem qualitativa do ser humano através de novos paradigmas. Ed. do autor, Florianópolis.

Stotz EN 1993. Enfoques sobre educação e saúde, pp. 1626. In VV Valla \& ED Stotz (orgs.). Participação popular, educação em saúde: teoria e prática. (2a ed.). Relume-Dumará, Rio deJaneiro.

Artigo apresentado em 7/10/2003

Aprovado em 15/6/2004

Versão final apresentada em 19/6/2004 